\title{
我国新型显示关键材料发展战略研究
}

\author{
高伟男，毕勇，刘新厚，许祖彦 \\ (中国科学院理化技术研究所, 北京 100190)
}

\begin{abstract}
摘要：新型显示作为电子信息领域为数不多的千亿美元级产业，是信息化、智能化时代我国战略性新兴产业重点发展方向之 一。本文针对新型显示关键材料与工艺在新型显示技术和产业发展进程中的战略性、支撑性和保障性作用开展论述，梳理了 具有代表性的新型显示关键材料的研究现状与发展趋势, 凝练了我国相关领域在材料技术和应用技术方面存在的问题，提出 了我国新型显示关键材料发展目标和重点方向。研究建议：抓牢新一轮显示技术升级与产业转型的重大机遇，从国家经济发 展全局的高度、全产业链生态的角度出发, 以整机应用为牵引, 以核心材料为突破口, 打造新型显示创新平台, 构建高效的 技术创新体系; 聚合优势力量, 突破产业化发展中的核心共性关键材料与工艺问题，完善产业协同创新生态。从技术、市场、 资金、政策等多个角度完成了新型显示创新平台的可行性分析，以期支持我国新型显示产业 “从跟随到引领” 的跨越式发展。 关键词：新型显示；有机发光二极管；微米级发光二极管；激光显示；关键材料
\end{abstract}

中图分类号: TN27 文献标识码：A

\section{Development Strategy of Key Materials for Novel Display in China}

\author{
Gao Weinan, Bi Yong, Liu Xinhou, Xu Zuyan \\ (Technical Institute of Physics and Chemistry, Chinese Academy of Sciences, Beijing 100190, China)
}

\begin{abstract}
Novel display is among the few industries in the electronic information field that is valued hundred-billion US dollars. It is also regarded as a significant direction for China's strategic emerging industries in the age of information and intelligence. Key materials and process technologies are critical for the novel display industry development. In this article, the status quo, development trend, and problems of the key materials and their application to the novel display industry in China are systematically analyzed, and the corresponding development goals and directions of the key materials are proposed. To seize opportunities created by technological upgrading and industrial transformation of the international display industry, China should establish a novel display innovation platform and build an efficient technological innovation system at the national level and from the perspectives of national economic development and the whole industrial chain. To this end, it should promote display applications and focus on breakthroughs regarding key materials. It also should improve the innovation ecology for industrial collaboration by integrating the advantages of interested parties to make breakthroughs regarding the common technologies of key display materials and processes. Furthermore, the feasibility analysis of the novel display innovation platform is conducted from the aspects of technology, market, funds, and policy, hoping to provide a reference for the transition of China from a follower to a leader in the novel display industry.
\end{abstract}

Keywords: novel display; organic light emitting diode (OLED); Micro-LED; laser display; key materials

收稿日期 : 2020-07-13; 修回日期 : 2020-08-27

通讯作者: 许祖彦, 中国科学院理化技术研究所研究员, 中国工程院院士, 主要从事激光技术及应用研究; E-mail: zyxu@mail.ipc.ac.cn 资助项目：中国工程院咨询项目 “新材料强国 2035 战略研究” (2018-ZD-03)

本刊网址：www.engineering.org.cn/ch/journal/sscae 


\section{一、前言}

自 1939 年第一台黑白电视机发明以来，显示 器这一人机界面终端显示设备逐渐应用于社会生活 的各个领域。时至今日，新型显示已成为电子信息 产业的核心技术之一，应用遍及工业、交通、通信、 教育、航空航天、娱乐、医疗等诸多方面, 形成了 千亿美元级市场规模，成为战略性高新科技领域的 基础性和最具活力的产业, 极大地改变了人类的生 活模式 [1]。当前, 多种显示技术创新涌现, 如有 机发光二级管（OLED）显示、量子点（QD）显示、 Micro-LED 显示 [2]、激光显示 (LD) 等 [3], 推动 着显示技术朝着高清化、全色化、大屏化、柔性化、 绿色化方向发展。光学、半导体、材料、视频、信 息等技术的相互融合进一步提升了显示产品的竞争 力、创新力和对终端消费者的吸引力。

经过多年发展, 我国显示产业成为全球重要组 成部分。2019 年，中国大陆新型显示产业综合规模 超过 3 万亿元, 成为世界显示面板产能第一大国, 正处于 “由大到强” 的发展机遇期。值得指出的是, 与先进国家相比, 我国在显示产业的上游领域中有 超过 $60 \%$ 的关键材料与装备依赖进口; 产业关键 环节尚难以自主可控，潜在发展壁垒日益显现。这 些都是制约我国新型显示产业实现跨越式发展的瓶 颈问题。

一代显示材料决定一代显示器件, 新型显示的 自主创新必然以相关材料的创新为基础。本文梳理 国内外新型显示关键材料体系与技术的发展现状和 前景趋势, 凝练我国产业发展面临的问题, 针对性 提出我国新型显示产业自主可控发展的措施建议。 通过宏观研究, 以期明晰未来技术制高点, 推动我 国新型显示产业实现高质量发展，尽快由显示大国 转变为显示强国。

\section{二、国外新型显示关键材料发展现状}

显示产业是涉及光电子材料与器件、光学工 程、微电子与电子学等领域的综合性产业, 新一代 技术变革往往由材料和器件的突破所带动。纵观显 示技术和产业发展的历程, 进入 21 世纪后以薄膜 晶体管液晶显示 (TFT-LCD) 为代表的第二代数字 平板显示技术逐渐成为主流。为应对需求，显示基
板尺寸在不断扩大，目前 G8.5 代线（及以上）的 大尺寸生产线成为主力, 相应的半导体 / 真空工艺 技术难度更高，对于资源的需求和投入也更大。

近年来, 随着第五代移动通信、大数据、人 工智能等新一代信息技术的出现, 新型显示与超高 清视频、柔性、传感、印刷电子等技术交叉融合, 丰富了新型显示终端产品体系。例如, 印刷显示、 Mini/Micro-LED 显示、激光显示、电子纸显示等新 型显示技术和产品基本具备了产业化条件, 引导了 显示材料、器件、装备到制造技术在内的整个显示 产业链的一次全面技术革新。

\section{（一）印刷显示及其关键材料}

印刷显示技术是使用喷墨打印的方式，将 $\mathrm{OLED} /$ 量子点发光二级管 (QLED) 材料所配制的 墨水喷打在所需要的像素位置, 实现显示器件制 作的技术。相应关键材料为印刷发光材料、墨水 等 [4]。国外在印刷显示产业及其关键材料方面的 布局较早, 具有雄厚的材料工艺与设备基础, 已进 行了商业化。

先进国家投入大量资源开展了关键材料、器件、 工艺、系统原型等方面的基础与应用研究。美国的 杜邦公司、Polyera 公司、Plextronics 公司, 欧洲的 默克集团、FlexInk 公司、Plastic Logic 公司等在印 刷小分子 OLED 材料、有机半导体材料、OLED 发 光材料、 $Q D$ 材料、有机薄膜晶体管 (OTFT) 背板 集成材料与制造工艺方面具有技术优势。相关研究 机构, 如美国的斯坦福大学、西北大学、加州大学 伯克利分校, 欧洲的剑桥大学、帝国理工学院、英 国印刷电子中心、芬兰国家技术研究中心、德国海 德堡创新实验室等, 也围绕上述材料和工艺提前布 局研究。

日本 JOLED 公司完成了 $20 \mathrm{in} / 230$ PPI 的样机 开发, 2018 年开始建设 G5.5 量产线; 住友化学株 式会社、东京电子株式会社/精工爱普生公司、凸 版印刷株式分社、大日本印刷株式会社等布局样机 和量产工艺研究。韩国乐金电子公司完成了 55 in 印刷 OLED 样机开发, 三星电子公司正在实施印刷 OLED/QLED 材料与技术研发。

\section{（二）蒸镀 OLED 显示材料}

基于蒸镀工艺的 OLED 显示技术，关键材料包 
括红绿蓝发光材料、空穴/电子传输材料、电极材 料等。相关发光材料可分为苂光材料、磷光材料, 根据分子量也可分为小分子发光材料、聚合物发光 材料 [5], 这些关键材料占 OLED 显示屏物料成本 的比例约为 $30 \%$ 。

日本、美国和韩国在 OLED 显示材料供应方面 具有优势。日本住友化学株式会社、昭和电工株式 会社等主要供应 OLED 聚合物发光材料, 日本出 光兴产株式会社、三井化学株式会社等是小分子 发光材料供应的龙头企业, 日本出光兴产株式会 社、韩国乐金化学公司成为 OLED 电子传输材料 的优势供应商, 日本德山株式会社、德国默克集 团、日本出光兴产株式会社是空穴传输材料的主 要供应商, 韩国三星 SDI 有限公司、美国环宇显 示技术股份有限公司、日本新日铁化学株式会社、 德国默克集团主要供应绿光磷光材料, 美国陶氏 化学公司、日本德山株式会社是红光磷光材料的 主要供应商。

\section{（三）激光显示及其关键材料}

激光显示是以红、绿、蓝三基色（或多基色） 激光为光源的新型显示技术, 具有大尺寸 / 超大尺 寸、大色域、超高清、高观赏舒适度等优点 [6,7], 关键材料包括三基色激光材料、超高清成像材料。

日本、韩国和美国在 20 世纪 90 年代启动了激 光显示关键技术研究布局, 通过美国能源部计划、 日本科技基本计划等国家项目予以引导, 支持相关 企业开展技术攻关。日本日亚化学株式会社、三菱 电机集团等已投入约 32 亿美元研发三基色 (半导 体激光器) 激光显示, 其中镓铟磷 (GaInP) 红光、 氮化镓 $(\mathrm{GaN})$ 蓝绿光激光显示的功率和寿命等关 键指标国际领先。美国德州仪器公司、日本索尼集 团等基本垄断了 $2 \mathrm{~K} / 4 \mathrm{~K}$ 分辨率的反射式数字微镜 (DMD)、反射式硅基液晶 ( LCOS) 等激光显示超 高清图像处理芯片供应。

\section{（四）Mini/Micro-LED 显示及其关键材料}

Mini/Micro-LED 显示是由微米级半导体发光 像元阵列组成的新型显示技术, 是显示技术与 LED 技术复合集成的综合性技术 [8]。GaN 发光材料与 高迁移率的半导体材料、驱动技术、巨量转移技术 等是 Mini/Micro-LED 显示的关键材料和技术。
在 10 余年前, Mini/Micro-LED 显示引起了 研究人员的关注。法国原子能委员会电子与信息 技术实验室 (CEA-LETI) 推出了面向虚拟现实/ 增强现实显示应用的全彩显示器件, 像素点尺 寸仅为 $10 \mu \mathrm{m}$ 。日本索尼集团在 2012 年发布的 55 in “Crystal LED Display”, 对比度可达百万比 一, 色彩饱和度可达 140\% NTSC（美国国家电视 标准委员会制定的彩色电视广播标准), 响应速度 快、使用寿命长; 2016 年日本索尼集团推出了 “模 块化拼接” 工艺, 即经多片模组拼接成更大尺寸显 示屏。2018 年, 韩国三星公司发布了大尺寸 Mini$\operatorname{LED}$ ( LED 尺寸约为 60 100 $\mu \mathrm{m}$ ) 显示墙样机和产品。

\section{（五） QD 显示及其关键材料}

$\mathrm{QD}$ 显示是利用发光 QD 材料的显示技术 [9], 根据发光形式的不同可分为光致发光和电致发光。 相应的关键材料为纳米尺寸的 QD 材料。

目前生产 $\mathrm{QD}$ 材料和 $\mathrm{QD}$ 背光源器件的上游企 业主要有美国 QD Vison 公司、Nanosys 公司, 英国 NANOCO 集团等。QD Vision 公司主要使用硒化镉 (CdSe) QD, Nanosys 公司和 NANOCO 集团则使 用磷化铟 (InP) QD; 由于欧盟禁售含镉元素（有 毒性) 的电子产品, CdSe 已淡出商业应用。韩国 的技术研发以三星电子公司为核心单位, 联合首尔 大学、韩国科学技术研究院等科研单位协作开展; 2016 年三星电子公司收购了 QD Vision 公司。其他 $\mathrm{QD}$ 材料, 如钻钛矿 QD、碳点, 属于新兴的 QD 材料研究方向, 有关研究正在逐步深化。

\section{（六）反射式显示及其关键材料}

反射式显示通常指通过反射环境光实现的类纸 型显示技术。目前主流技术分为电泳电子纸、电润 湿电子纸、胆甾相液晶电子纸等, 相应的应用终端 有电子书、移动终端显示、辅助显示屏、智能电子 标签等。相关的关键材料有: 彩色显示材料 (颗粒 体系和溶液体系) 、介电润湿材料、高透过/高反射 TFT 背板材料、像素结构材料等 [10]。

美国亚马逊公司、德国 ADT 集团、荷兰 Etulipa 公司是反射式显示技术的优势公司。2017年, 美国 CLEARink Display 公司也发布了全彩视频化 显示电子纸样机, 能以 $30 \mathrm{fps}$ 的帧率播放全彩视频。 2018 年, Plastic Logic 公司在电子纸像素密度提升 
方面取得突破，所发布的 10.8 in 显示屏的分辨率达 到 500 PPI。

\section{（七）其他显示及其关键材料}

液晶显示作为当下主流的显示产品, 涉及液晶、 玻璃基板、光学膜三大基础材料 [11]。在高端液晶 材料市场方面, 德国默克集团, 日本智索株式会社、 DIC 株式会社、ADK 公司等具有主导优势。在玻 璃基板材料方面, 美国康宁公司、日本旭硝子株式 会社等具有市场主导地位。在光学薄膜方面, 中高 档光学薄膜产品主要来自日本东丽株式会社、美国 明昵苏达矿业及机器制造 (3M) 公司、韩国 SKC 有限公司，大部分关键原料具有较高的技术门槛。

柔性显示是由柔性电子元件组装而成的可以卷 起变形的显示器, 在移动设备、可穿戴设备等领域 有着广阔的前景 [12]。相关的关键材料是柔性基板 材料。聚酰亚胺（PI）基板具备优异的耐热性能和 尺寸稳定性, 是目前唯一能够胜任柔性 OLED 基板 的材料, 成为柔性 OLED 显示的关键核心材料。目 前, 美国和日本公司, 如杜邦公司、宇部兴产株式 会社、钟渊化学工业株式会社、东丽株式会社在耐 高温电子级 PI（黄色)、光学级 PT (无色透明) 供 应方面具有垄断性地位, 销售量占全球 PI 市场的 $70 \%$ 以上。2019 年折叠屏手机产品成功商业化, 伴 随着柔性显示技术的扩大应用, 未来 PI 的需求量 将稳步增长。

\section{三、国内新型显示关键材料发展现状}

\section{（一）新型显示产业政策环境不断优化，产业规模 处于领先}

我国重视新型显示产业的发展, 出台了《国家 中长期科学和技术发展规划纲要(2006-2020 年)》、 “中国制造 2025” 重点领域技术路线图等文件。在 国家科技重大专项、863 计划、973 计划、国家科 技支撑计划、国家重点研发计划等国家级科技和产 业计划的持续支持下, 我国已经从最初的显示屏幕 完全依赖进口发展为目前具有较高的自给率; 在 OLED、QD 显示、Micro-OLED 显示、激光显示、 电子纸显示、三维（3D）显示等细分领域也取得了 长足的技术进步, 保障了新型显示技术和产业的可 持续发展。
截至 2019 年，我国已投产产线约 45 条，后续 将有约 19 条 G8.5 代线 (及以上)、20 条有源矩阵 有机发光二极体 (AMOLED) 量产线投入使用; 累 计投资约 1.3 万亿元, 产业规模超过 3 万亿元。我 国相关产业成为全球规模最大、市场最大、竞争力 较强的产业, 全球显示产业正加速向我国转移。例 如, 国产显示面板占全球总产量的 $50 \%$, 电视屏幕 占比为 $70 \%$, 电脑和手机产量超过 $90 \%$ 。

相应地, 我国显示市场的快速发展推动了显示 关键材料需求的进一步扩大。例如, OLED 发光材 料的需求量预计到 2021 年将超过 $159 \mathrm{t}$, 年均增速 达到 $30 \%$ 。激光显示用三基色半导体激光器的需求 量预计到 2022 年将超过 $5 \times 10^{9}$ 只。2021 年液晶显 示 G8.5 以上基板玻璃的需求将增加到 $3.6 \times 10^{8} \mathrm{~m}^{2}$ 。 同时玻璃背盖板、3D 盖板、柔性盖板需求量也在 持续攀升。

\section{（二）技术创新能力持续增强，新型显示材料获得 创新应用}

科研院所、高等学校和企业在新型显示相关 的关键材料、器件及工艺技术的基础研究和应用方 面开展了大量工作, 积累了良好基础。(1)在液晶显 示方面, 国内机构开始重视技术自主创新, 掌握了 LCD 显示器件的大规模生产技术, 具备了显示面板 大规模生产能力, 培养了一批技术和生产骨干; 以 京东方科技集团股份有限公司、石家庄诚志永华显 示材料有限公司等为代表的一批企业, 围绕产业上 游的玻璃基板、偏光片、液晶材料、薄膜材料等开 展攻关并获得局部突破，使得相关材料的国产化率 稳步提升。(2)在 OLED 显示材料方面, 广州华睿光 电材料有限公司、北京鼎材科技有限公司、吉林奥 来德光电材料股份有限公司、西安瑞联新材料股份 有限公司等企业正在重点研发 OLED 材料。(3)具有 轻薄、柔性、大面积、绿色制造等特点的印刷显示 技术近年来发展迅速, 广东聚华印刷显示技术有限 公司、纳晶科技股份有限公司、华南理工大学、福 州大学、浙江大学、中国科学院长春应用化学研究 所等机构纷纷布局研究并实现了原理验证。

此外, 我国在激光显示、Micro-LED 显示等方 面的技术发展迅速。(1)在激光显示方面, 我国技术 水平整体上与国际同步, 产业规模国际领先; 围 绕激光显示核心关键材料, 如三基色激光显示、超 
高清成像芯片、光学镜头、高增益屏幕等实施重点 攻关; 中国科学院理化技术研究所、半导体研究 所、苏州纳米技术与纳米仿生研究所, 中国科学技 术大学, 青岛海信激光显示股份有限公司, 长虹激 光显示科技公司, 深圳光峰科技股份有限公司, 成 都菲斯特科技有限公司等研究单位和企业正在快速 缩短与国外的差距, 部分产品已经实现国产。(2)在 Mini/Micro-LED 显示方面, 国内重点研究 GaN 外 延材料、有源基板材料、用于巨量转移和彩色化显 示的特种显示材料, 相关单位有深圳市华星光电技 术有限公司、天马微电子股份有限公司、南方科技 大学、中国科学院微电子研究所、熊猫电子集团有 限公司等。

\section{四、我国新型显示关键材料发展面临的问题}

我国新型显示产业虽然已有规模优势, 但是全 产业链发展不均衡, 关键材料与装备对外依存度较 高, 利润率整体偏低, 产业发展存在隐患。国内产 业技术积累与国外企业尚存在较大差距, 关键原材 料更是 “卡脖子” 问题。在我国新型显示材料与国 际先进水平存在差距的背景下, 尽管国内涉足显示 材料的企业、科研院所、高等学校数量很多, 也取 得了一定的整体性进展, 但在关键材料产业化应用 方面始终是薄弱环节。

\section{（一）关键材料对外依存度高}

我国显示产业依然处于 “大而不强” 的局面。 国内平板显示产业优势在于系统集成和生产制造, 而在关键材料及工艺、元器件及制备技术、辅助材 料、高端设备等方面依然具有较高的对外依存度, 如超过 $70 \%$ 的相关材料依靠进口。国内主要从事 加工制造, 处于整个显示产业链条的底端, 技术含 量较低且利润微薄。

与新型显示关键材料相关的核心基础专利技术 集中于欧美企业, 产品和工艺方面的核心专利技术 主要由日本和韩国的企业掌握。TFT-LCD 显示的高 端液晶材料由德国、日本企业长期垄断, 曝光机由 日本企业垄断, TFT-LCD 用玻璃基板大部分依赖美 国、日本厂商进口。OLED 显示发光材料依赖美国、 日本、韩国等企业进口。激光显示商用化的核心材 料, 包括三基色发光材料、成像材料同样依赖进口。
对于印刷显示这一未来大尺寸/柔性 OLED 显示的 主流技术, 材料墨水主要由日本、德国和美国公司 主导。

\section{（二）部分产业“小、杂、散” 问题突出, 市场竞 争力不强}

新型显示材料的开发过程周期长、投资大、爬 坡慢, 国内企业的经营发展压力较大, 主打产品价 格依然处于相对低位。对这些企业而言, 先期的技 术积累和研发耗费了大量资源和资金, 而持续高额 投资构成了极大挑战。以 OLED 显示领域为例, 我 国面板制造商都在针对移动市场积极扩张面板产 能, 新成立的 OLED 材料生产企业超过 20 家; 相 关企业研发力量薄弱, 缺乏统一部署和长远规划, 资金投入小而分散, 技术应用以短平快为主; 主要 生产供应 OLED 材料的中间体和粗品, 成为国外优 势 OLED 材料公司的原材料供应商, 导致中高端产 品占比和产品附加值较低。

\section{（三）高端产品自给率不高, 高端应用的自主保障 能力不足}

我国在新型显示关键材料领域已有长足进步, 材料特性获得明显提升。但是相比国外优势企业还 存在很大差距, 突出表现为材料稳定性和寿命。以 激光显示领域为例, 国内相关产业发展增长迅速, 体现在产品种类不断增多、市场认可度逐渐提升, 市场规模不断扩大, 总体水平接近国际先进; 国内 企业已具有中高端激光显示产品的研制能力, 但在 红、绿、蓝三基色激光显示材料器件, 超高清视频 图像调制器件, 超短焦镜头, 屏幕膜片等激光显示 核心材料方面存在明显的短板。由于相关材料基本 被国外企业垄断, 导致国产中高端激光显示产品的 生产成本大幅提高, 制约了产业的发展空间。

\section{五、对我国新型显示关键材料发展的思考}

\section{（一）产业发展目标}

显示产业在我国经济发展中举足轻重, 未来 5 10 年将是争取产业发展主动权的关键时期。在显 示产业转型发展的重要节点, 应论证新型显示关键 材料的战略制定与规划部署, 致力于由长期的跟随 发展转变为引领未来的技术和产业创新发展。 
到 2025 年，新型显示材料总体技术和应用与 国际先进水平同步，关键高端材料实现自主可控保 障; 形成围绕新型显示材料、技术与应用的创新平 台，有效解决产业发展紧缺材料。

到 2030 年, 上下游协同创新体系及评价、标 准等公共服务平台全面建成, 打造覆盖材料、器件 和整机的产业链生态; 提升关键材料技术成熟度、 持续创新能力和产品市场竞争力, 实现关键材料国 产化率的进一步提升。

到 2035 年, 形成具有自主知识产权的新型显 示关键材料体系, 实现在国民经济重大领域中的全 面自主保障; 支撑新型显示产业聚集, 推动技术、 产业和人才水平达到国际领先, 跻身世界显示材料 强国行列。

\section{（二）总体发展思路}

新型显示关键材料具有研发投入大、技术流程 长、投资风险高等特点，属于人才/投入 / 资源密 集型产业。目前, 在国际平板显示产业发展速度趋 缓的形势下，我国相关产业呈现出逆势而上的良好 发展势头, 但是上游关键材料大部分依赖进口，巨 大的产业规模与风险并存。

为了确保我国显示产业的自主可控安全发展, 亟需构建顶层设计, 以材料突破为引领, 围绕新型 显示材料、器件及系统的应用开展全链条部署; 打 通产业链各技术环节, 以核心材料突破带动全局突 破，破解新型显示技术瓶颈和产业缺失技术的现实 问题; 推动材料、技术、装备的国产化转变, 提升 新型显示产业的核心竞争力。

\section{（三）重点发展方向}

显示产业进入了更新换代 “大洗牌” 的新阶段, 在未来很长的一段时间内, 各种显示技术将在各自 优势应用领域共存、多元化发展, 有望呈现百花齐 放、全面发展的特征。实施新型显示关键材料和关 键技术攻关行动, 提升关键材料成熟度、持续创新 能力和产品市场竞争力, 重点发展方向如下。

发展具有自主知识产权的蒸镀 OLED 材料、印 刷 OLED 材料, 提升蒸镀材料和印刷墨水的性能, 完善全球专利布局。

发展窄谱宽、高效率、长寿命的环保型 QD 发 光材料, 以及百千克级材料产量的量产工艺, 提升
产品的创新能力。

发展 Micro/Mini-LED 应用的大面积、低成本 GaN 外延材料和高迁移率、高稳定性有源基板材料, 解决巨量转移及键合、色彩转换、光效提取等关键 技术难题。

以整机应用为牵引, 突破短波长铝镓铟磷红光、 长波长铟镓氮蓝绿光等激光显示发光材料工艺, 发 展 $4 \mathrm{~K} / 8 \mathrm{~K}$ 超高分辨、快响应成像芯片, 补齐短板以 提升新材料的持续供给能力。

发展彩色显示材料、介电润湿材料、像素结 构材料等新一代反射式显示材料, 支撑在低功耗、 视觉健康、低光热辐射、可柔性显示器件等方向 的应用。

发展玻璃基板玻璃、高铝盖板玻璃、高分辨率 玻璃材料与量产工艺等显示基板材料和技术，实现 高世代应用的国产替代。

\section{六、发展建议一一新型显示创新平台}

\section{（一）平台建设和运行}

作为涵盖材料、设备、面板、终端产品在内的 完整体系, 新型显示需要发挥国家级产业政策引导 作用, 聚集国内优质创新资源, 实行 “政产学研” 协同创新。打造新型显示创新平台, 是契合未来显 示产业发展趋势、构建显示产业生态链的重要举措, 也是把握新一代显示技术与产业变革转型机遇、引 领产业国际技术创新合作与竞争的有力依托。

在平台建设思路上, 应由国家引导, 聚集显 示行业中材料、工艺、器件方面的优势机构, 联合 开展新型显示关键技术攻关; 作为公共开放平台, 应聚焦印刷显示、OLED 显示、激光显示、Micro/ Mini-LED 显示等新型显示关键材料的研发。

平台运营按照市场化原则, 以技术为导向, 以 市场为埽引, 为上下游企业提供开放共享的研发、 中试与服务; 通过技术转让、产业孵化、平台技术 服务、知识产权收益等机制逐步实现 “自我造血”; 形成我国显示核心技术的供给源头、区域产业集聚 发展的创新高地、新型显示人才培养与输出地。

\section{（二）平台风险分析}

对于新型显示技术及其关键材料, 世界显示 强国已进行了较充分的发展策略探讨和基础研究布 
局, 技术积累亦较为丰富。我国开展平台建设和重 点方向攻关，技术路径选取方面的风险不大。

在市场风险方面，新型显示契合大屏化、柔性 化、高清化、透明化、立体化、智能化、低成本的 技术和产品趋势, 将是未来产业发展的必然方向。 新型显示材料的发展较好聚焦了上述应用方向和场 景特性，可以给出技术方向明确、市场风险可控的 基本判断。

在资金风险方面，平台获得国家先导资源支持， 以具有资金实力的企业为主体，发挥公有与市场资 源的结合优势，降低投融资风险；平台的技术成果 能够实施快速市场转化，在投资价值最大化的同时 带动新型显示产业的快速发展、结构升级。因此资 金风险可控。

在市场竞争力方面，平台可以聚集国内优势资 源，建立涵盖基础研究、共性关键技术研发、测试 验证、产业化应用在内的完整生态; 配套实施专利 池建设和人才培养, 将全面提升我国新型显示行业 的国际竞争力。

\section{参考文献}

[1] 高伟男, 许祖彦, 毕勇, 等. 激光显示技术发展的现状和趋势 [J]. 中国工程科学, 2020, 22(3): 72-77.

Gao W N, Xu Z Y, Bi Y, et al. Present development and tendency of laser display technology [J]. Strategic Study of CAE, 2020, 22(3): 72-77.

[2] Huang Chen S, Huang Y M, Singh K J, et al. Full-color Micro-LED display with high color stability using semipolar (2021) InGaN LEDs and quantum-dot photoresist [J]. Photonics Research, 2020, 8(5): 630-636.
[3] 许祖彦, 毕勇, 张文平. 激光显示是我国新型显示技术发展主流 [J]. 电子科学技术, 2019 (1): 53-61.

Xu Z Y, Bi Y, Zhang W P. Laser displays: Developing trend of Chinese new display technology [J]. Electronic Science \& Technology, 2019 (1): 53-61.

[4] 史冬梅, 杨斌, 刘红丽. 印刷与柔性显示材料与器件技术发展现 状与趋势 [J]. 科技中国, $2018(3)$ : 16-18.

Shi D M, Yang B, Liu H L. Present development and tendency of printing and flexible display material and device [J]. China SciTechnology Business, 2018 (3): 16-18.

[5] 高鸿锦, 董友梅. 新型显示技术 [M]. 北京: 北京邮电大学出版 社, 2014 .

Gao H J, Dong Y M. New display technology [M]. Beijing: Beijing University of Posts and Telecommunications Press, 2014.

[6] Chellappan K V, Erden E, Urey H. Laser-based displays: A review [J]. Applied Optics, 2010, 49(25): 79-98.

[7] 许祖彦. 光电子晶体与全固态激光器及其应用一一光电子技术 发展的一个重大方向 [J]. 中国工程科学, 1999, 1(2): 72-77.

Xu Z Y. Optoelectronic crystals, all-solid-state lasers and their applications - An Important course of optoelectronics R \& D [J]. Strategic Study of CAE, 1999, 1(2): 72-77.

[8] Lee V W, Twu N, Kymissis I. Micro-LED technologies and applications [J]. Information Display, 2016, 32(6): 16-23.

[9] Ekimov A I, Onushchenko A. Quantum size effect in three-dimensional microscopic semiconductor crystals [J]. JETP Letters, 1981, 34(6): 345-349.

[10] Kao W C, Chang W T, Ye J A, et al. Driving waveform design based on response latency analysis of electrophoretic displays [J]. Journal of Display Technology, 2012, 8(10): 596-601.

[11] 张芳. 新型平板显示技术和产业发展战略 [M]. 北京: 中国科技 出版传媒股份有限公司, 2011.

Zhang F. The development strategy of new display technology and industry [M]. Beijing: China Science Publishing \& Media Ltd., 2011.

[12] Crawford G P. Flexible flat panel display technology [M]. New York: John Wiley \& Sons Ltd., 2005. 